\title{
Use of Complementary and Alternative Medicine among Patients with End-Stage Renal Disease
}

\author{
Gurjeet S. Birdee, ${ }^{1,2}$ Russell S. Phillips, ${ }^{3}$ and Robert S. Brown ${ }^{4}$ \\ ${ }^{1}$ Division of General Internal Medicine \& Pediatrics, Department of Medicine, Vanderbilt University Medical Center, \\ Nashville, TN 37232, USA \\ ${ }^{2}$ Vanderbilt Center for Integrative Health, Vanderbilt Center for Health Services Research, Vanderbilt University Medical Center, \\ Suite 6000 Medical Center East, Nashville, TN 37232-8300, USA \\ ${ }^{3}$ Division of General Medicine and Primary Care, Beth Israel Deaconess Medical Center, Boston, MA 02215, USA \\ ${ }^{4}$ Division of Nephrology, Department of Medicine, Beth Israel Deaconess Medical Center, Boston, MA 02215, USA \\ Correspondence should be addressed to Gurjeet S. Birdee; gurjeet.birdee@vanderbilt.edu
}

Received 31 January 2013; Accepted 31 March 2013

Academic Editor: Svein Haavik

Copyright @ 2013 Gurjeet S. Birdee et al. This is an open access article distributed under the Creative Commons Attribution License, which permits unrestricted use, distribution, and reproduction in any medium, provided the original work is properly cited.

Among patients with end-stage renal disease (ESRD), few studies have examined the use of complementary and alternative medicine (CAM) and patients' interest in learning mind-body interventions to address health issues. We surveyed 89 adult patients (response rate $84 \%$ ) at an outpatient hemodialysis center in Brookline, MA, USA regarding the utilization of CAM, including mind-body practices, and willingness to learn mind-body practices. Of respondents, $47 \%$ were female, $63 \%$ were black, and mean age was 62 years. $61 \%$ reported using CAM for health in their lifetime, and 36\% reported using CAM within a month of the survey. The most frequent CAM modalities reported in ones' lifetime and in the last month were mind-body practices ( $42 \%$ and $27 \%$, resp.). Overall lifetime CAM use did not differ significantly by sex, race, dialysis vintage, diagnosis of ESRD, employment status, or education level. Subjects reported that mind-body interactions were very important to health with a median score of 9 on a 10-point Likert scale (ranging from 0 for not important to 10 for extremely important). Most patients (74\%) reported interest in learning mind-body practices during maintenance hemodialysis. In summary, CAM use, particularly mind-body practice, is frequent among patients with ESRD providing opportunities for future clinical research.

\section{Introduction}

Over half a million individuals in the USA have end-stage renal disease (ESRD), and about 400,000 receive maintenance hemodialysis (MHD) to sustain their life [1]. Despite significant medical advances over several decades, the survival of patients on MHD remains drastically shorter than the general population with a reported 5-year survival rate of $35 \%$ in the USA [1]. Cardiovascular diseases account for $50 \%$ of mortality [1], in part due to a disproportionate burden of cardiovascular risk factors such as hypertension, diabetes, dyslipidemia, and sedentary behavior [2]. Patients receiving MHD also experience lower health-related quality of life [3,4] and physical functioning [5-7] as compared to healthy individuals with normal kidney function and suffer from a high prevalence of mood disorders $[8,9]$. A majority of research on improving health outcomes for patients on MHD has focused on pharmacotherapy and delivery of MHD [10], with less research in the area of behavioral interventions such as exercise [11-14]. While initial research suggests that exercise may improve health-related outcomes among patients with ESRD [15, 16], implementation has been challenging $[12,17]$. Investigators have studied exercise prescription outside of and during dialysis sessions, and intradialysis exercise may have a higher adherence than extradialysis exercise $[15,18]$.

Complementary and alternative medicine (CAM) may provide new therapeutic options for patients with ESRD with the goal of improving symptoms and quality of life. CAM, as defined by the National Center for Complementary and Alternative Medicine, is "a group of diverse medical and 
health care systems, practices, and products that are not generally considered to be a part of conventional medicine" [19]. Based on national survey data, four out of 10 adults in the USA have used some type of CAM in the last 12 months [20]. The most commonly used CAM modalities include biologically based products (herbs and dietary supplements) and mind-body practices (e.g., yoga, tai chi, deep breathing, and meditation). However, there are limited data on the use of or interest in CAM therapies among patients with chronic kidney disease including those with ESRD [2123]. In particular, mind-body practices may provide a novel behavioral treatment for patients on MHD to reduce comorbid symptoms and conditions associated with this complex chronic disease. Similar to exercise, mind-body intervention could potentially be delivered during MHD; though patients' willingness to practice mind-body techniques is unknown. The purpose of this study among patients with ESRD on MHD was to identify the frequency of prior CAM use, including mind-body practices, attitudes towards mind-body practices, and willingness to learn or participate in studies of mind-body practices during MHD.

\section{Methods}

2.1. Study Population. All patients with ESRD receiving MHD at a private dialysis center in Brookline, MA, USA, affiliated with a large academic medical center from September 2009 to July 2010 were approached to participate in the study. Potentially eligible patients were approached chair side during their dialysis session and asked to participate in the study. Subjects were excluded from the study if they were younger than 18 years, non-English speaking, or had a diagnosis of dementia. Willing patients gave verbal consent to participate.

2.2. Survey Instrument and Data Collection. A 40-item questionnaire was administered by the principal investigator (GB) to subjects face-to-face, chair side, during MHD (see Table 1 complementary and alternative medicine questionnaire). Questionnaire items were adapted from National Health Interview Survey Adult Complementary and Alternative Medicine Supplement, a nationally representative survey administered by the CDC in 2007 [20]. Items were selected based on content to determine the prevalence of CAM use in the subject's lifetime and the last month. In addition, we asked questions to explore patients' perception of mind-body practices including importance of mind-body interactions for health, willingness to learn mind-body techniques, and interest in participating in a study of mind-body techniques during MHD. In addition to the survey, data were available on age, gender, race, dialysis vintage, and principal ESRD diagnosis for all study subjects. Data on employment status, educational level, and BMI were available on a majority, but not all research subjects.

2.3. Statistical Analysis. Data were analyzed using descriptive statistics for CAM use by demographics including age, sex, race, dialysis vintage, diagnosis of ESRD, and if data were

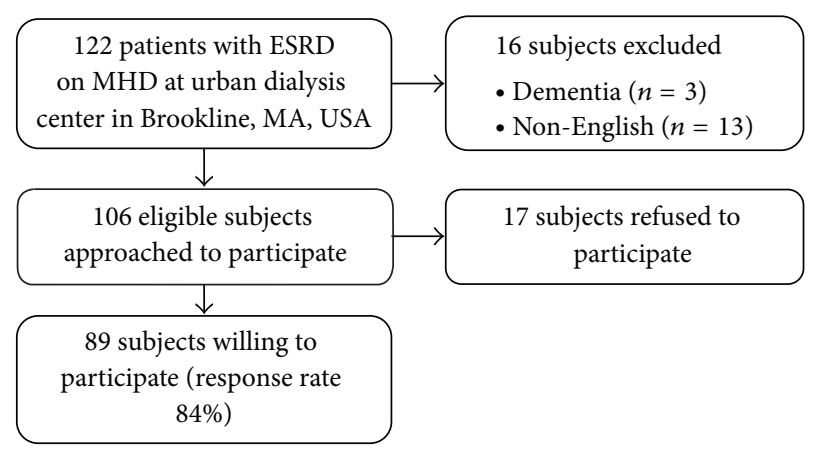

FIGURE 1: Flow diagram for survey.

available, employment status, education level, and body mass index (BMI). Individual CAM therapies were grouped into 5 major categories as defined by the National Center for Complementary and Alternative Medicine: (1) biologicallybased practices (herbal supplements); (2) manipulative/body-based practices (chiropractic, massage); (3) mindbody-based practices (yoga, tai chi, qigong, meditation, guided imagery, progressive relaxation, and deep breathing exercises); (4) alternative medical systems (acupuncture, homeopathy, naturopathy, ayurveda, and traditional healers); and (5) energy healing (Reiki). For analyses, we excluded vitamins from biologically based practices since vitamins are usually prescribed as a conventional therapy for MHD patients in the USA. All CAM therapies were combined to a single category to identify any CAM use in a lifetime and the last month. Continuous variables were reported as medians with 25th and 75th interquartile ranges and categorical variables as frequencies and proportions. Categorical variables were compared with Fischer's exact test. The study was approved by the Institutional Review Board at Beth Israel Deaconess Medical Center.

\section{Results}

Among 106 eligible subjects approached, 89 subjects were willing to participate corresponding to a response rate of $84 \%$ (see Figure 1 for flow diagram of survey). Of those subjects excluded from the study, 3 patients had dementia, and 13 patients were non-English speakers. The surveyed sample was $47 \%$ female, $63 \%$ black, and had a mean age of 62 years. Fifty-four of the patients (61\%) reported using CAM anytime in their lifetime (Table 2). The most frequent modalities reported were mind-body practices (used by $42 \%$ ) and manipulation and body-based practices (used by $34 \%$ ). The most common mind-body practices reported were deep breathing exercises (27\%), meditation (26\%), yoga (11\%), progressive relaxation (9\%), and tai chi (6\%). Table 3 reports patients' characteristics and lifetime use of overall CAM by patient characteristics. CAM use was distributed throughout the population in regards to race, employment status, dialysis vintage, principal diagnosis of ESRD, and BMI. CAM use varied significantly by age as overall CAM $(P=0.02)$, alternative medical systems $(P=.03)$, and manipulation and body-based practices ( $P=0.01)$ were used most commonly 
TABLE 1: Complementary and alternative medicine questionnaire ${ }^{\mathrm{a}}$.

Question

(i) Have you ever used any of the following for your health?

(a) If yes, have you used (CAM modality) in the last month?

Listed options: acupuncture, ayurveda, biofeedback, chelation therapy, and chiropractic care or chiropractor, energy healing therapy or reiki, and folk medicine such as curanderismo or native American healing, hypnosis, massage, and naturopathy

(i) Have you ever used natural herbs or dietary supplements for your health? For example ginger,

Echinacea, or black cohosh

Response choices

(ii) Have you used natural herbs or dietary supplements in the last month?

(i) Have you ever used any of the following mind-body techniques for your health?

(a) If yes, did you use (CAM modality) in the last month?

Listed options: meditation, guided imagery, progressive relaxation, deep breathing exercises, Yoga, tai Chi andqigong

(i) Using a scale from 0 to 10 (where 0 is not at all important and 10 is extremely important) in your opinion, how important are mind-body interactions to your health?

(i) Would you be interested in learning mind-body techniques at no cost to you?

(i) If respondent stated no: Why are you not interested in learning mind-body techniques?

Listed options: $i$ am not interested, mind-body techniques do not work, $i$ do not have time, $i$ won't be

able to learn, $i$ donot have the energy, i am too sick, $i$ donot have the money, i do not have a place to

learn, and other

(i) If your doctor agreed, would you be interested in a study that would teach you mind-body

No, yes, do not know

techniques that you would practice during dialysis?

${ }^{a}$ Adapted from the National Health Interview Survey Adult Complementary and Alternative Medicine Supplement.

TABle 2: Prevalence of any CAM use and CAM modalities among patients with ESRD on MHD $(n=89)$.

\begin{tabular}{lc}
\hline CAM modality & Prevalence (\%) \\
\hline Any CAM use & 61 \\
Alternative medical systems & 17 \\
Manipulation and body-based practices & 30 \\
Biologically based products & 14 \\
Mind-body practices & 42 \\
\hline
\end{tabular}

by patients aged between 50 and 64 years ( $80 \%$ overall used CAM) and by only $36 \%$ of patients of age 80 years or older. While CAM use was more common in females than males (69\% versus $53 \%, P=0.055$ ) and those with college or higher education than those with high school or less education $(79 \%$ versus $56 \%, P=0.075$ ), observed differences did not reach statistical significance. In the last month, $36 \%$ of patients reported using some type of CAM. The most frequent CAM modality used in the last month by patients was mind-body practice $(27 \%)$, while biologically based practices excluding vitamins were used in the last month by $15 \%$ of patients.

Subjects reported the perception that mind-body interactions were important to their health with a median score of 9 (interquartile range: 5,10 ) on a 10 point Likert scale from 0 to 10 . Table 4 reports the frequency of interest in learning mind-body practices among patients on MHD. A majority of patients reported interest in learning mind-body practices (70\%) and participating in a study of intradialysis mindbody practice $(74 \%)$. Almost half of individuals 80 years or older were interested in learning mind-body practices. Most patients who had used CAM reported interest in participating in a mind-body study during MHD (87\%), while only 54\% who never used CAM reported interest in participation. The most common reasons for which patients were not interested in learning mind-body practices were lack of interest $(n=$ $21)$, lack of time $(n=5)$, and perception of inability to learn $(n=4)$.

\section{Discussion}

In our sample population, $61 \%$ of patients with ESRD on MHD reported a lifetime use of CAM with 36\% reporting use within a month of the survey. The most common modality used by patients in a lifetime or during the last month was mind-body practices. A majority of patients felt that the mind-body connection was very important for their health. An estimated 3 out of 4 patients were interested in learning mind-body practices and participating in research regarding mind-body practices during MHD.

Limited studies have been conducted identifying patterns of CAM use among patients with chronic disease. National surveys have reported a high overall prevalence of CAM use among patients with arthritis (60\%), lung disease (55\%), cardiovascular disease (46\%), and diabetes (41\%) [24]. Prior surveys have reported a wide range of CAM prevalence among patients with ESRD [21-23]. A study conducted in Cincinnati surveyed 153 patients receiving dialysis (both $\mathrm{HD}$ and peritoneal) and found $18.3 \%$ of patients had used or currently were using CAM [21]. A survey of patients who received renal transplants in Switzerland $(n=356)$ reported $12 \%$ prevalence of CAM use [22]. These surveys did not include questions regarding specific mind-body practices such as deep breathing exercises, meditation, yoga, or tai 
TABLE 3: Lifetime prevalence of overall CAM use among patients with ESRD on MHD by patient characteristics (\%) .

\begin{tabular}{|c|c|c|}
\hline & $\begin{array}{c}\text { No CAM } \\
\text { use } \\
(n=35)\end{array}$ & $\begin{array}{c}\text { Any CAM } \\
\text { use } \\
(n=54)\end{array}$ \\
\hline Percentage of all patients & 39 & 61 \\
\hline \multicolumn{3}{|l|}{ Age (years) ${ }^{b}$} \\
\hline $18-34$ & 9 & 4 \\
\hline $35-49$ & 20 & 15 \\
\hline $50-64$ & 20 & 52 \\
\hline $65-79$ & 31 & 22 \\
\hline$\geq 80$ & 20 & 7 \\
\hline Female & 37 & 54 \\
\hline \multicolumn{3}{|l|}{ Race } \\
\hline White & 29 & 30 \\
\hline Black & 63 & 63 \\
\hline Other & 9 & 8 \\
\hline \multicolumn{3}{|l|}{ Dialysis vintage (years) } \\
\hline$<1$ & 23 & 30 \\
\hline $1-4$ & 34 & 44 \\
\hline $5-9$ & 34 & 17 \\
\hline$\geq 10$ & 9 & 9 \\
\hline \multicolumn{3}{|l|}{ Principal ESRD diagnosis } \\
\hline Diabetes mellitus & 49 & 61 \\
\hline Hypertension & 20 & 9 \\
\hline Glomerulonephritis & 9 & 11 \\
\hline HIVAN & 6 & 6 \\
\hline Other & 17 & 13 \\
\hline Employment status & $(n=34)$ & $(n=51)$ \\
\hline Employed full or part time & 12 & 18 \\
\hline Retired & 53 & 24 \\
\hline Disabled & 35 & 59 \\
\hline Education level & $(n=27)$ & $(n=41)$ \\
\hline Postgraduate degree & 7 & 12 \\
\hline College degree & 4 & 15 \\
\hline $\begin{array}{l}\text { Vocational or high school } \\
\text { degree }\end{array}$ & 70 & 61 \\
\hline Grade school or lower & 19 & 12 \\
\hline $\mathrm{BMI} \pm \mathrm{SD}$ & $\begin{array}{c}(n=23) \\
30.3 \pm 10.7\end{array}$ & $\begin{array}{c}(n=41) \\
26.3 \pm 6.3\end{array}$ \\
\hline
\end{tabular}

CAM: complementary and alternative medicine; ESRD: end-stage renal disease; MHD: maintenance hemodialysis; HIVAN: HIV-associated nephropathy; and BMI \pm SD: body mass index \pm standard deviation.

${ }^{a}$ Figures are percentages of patients based on the number $(n)$ in each group.

${ }^{b}$ Within group differences significant between any CAM use or CAM modality and no CAM use with $P<0.05$ by Fisher's exact test.

chi. Mind-body practices were the most common CAM modalities we identified in our sample. Comparison of these studies to our own is difficult due to varying definitions of CAM utilized. Our survey represents the first study of CAM use as defined by the National Center for Complementary and Alternative Medicine among patients with ESRD on MHD.
TABLE 4: Interest in learning mind-body practices among patients on MHD (\%).

\begin{tabular}{|c|c|c|}
\hline & $\begin{array}{l}\text { Interest } \\
\text { learning } \\
\text { MBP (\%) }\end{array}$ & $\begin{array}{l}\text { Interest in participating } \\
\text { in study of MBP during } \\
\text { MHD (\%) }\end{array}$ \\
\hline Total $(n=89)$ & 70 & 74 \\
\hline \multicolumn{3}{|l|}{ Age (years) } \\
\hline $18-34$ & 100 & 100 \\
\hline $35-49$ & 54 & 69 \\
\hline $50-64$ & 71 & 74 \\
\hline $65-79$ & 78 & 78 \\
\hline$\geq 80$ & 46 & 46 \\
\hline \multicolumn{3}{|l|}{ Gender } \\
\hline Female & 74 & 74 \\
\hline Males & 66 & 75 \\
\hline \multicolumn{3}{|l|}{ Race } \\
\hline White & 54 & 65 \\
\hline Black & 76 & 74 \\
\hline Other & 71 & 100 \\
\hline \multicolumn{3}{|c|}{ Dialysis Vintage (years) } \\
\hline$<1$ & 75 & 79 \\
\hline $1-4$ & 68 & 74 \\
\hline $5-9$ & 78 & 89 \\
\hline$\geq 10$ & 50 & 50 \\
\hline \multicolumn{3}{|c|}{ Ever used CAM use } \\
\hline No & 62 & 54 \\
\hline Yes & 74 & 87 \\
\hline
\end{tabular}

MBP: mind-body practices and MHD: maintenance hemodialysis.

Our results suggest a positive perception of and willingness to learn mind-body practices among patients on MHD, including during hemodialysis, especially among those patients who have familiarity with CAM. Three small studies have suggested that mind-body practices may be useful for patients with ESRD [25-27]. However, no prior studies have examined the role of mind-body practices during MHD. Conventional exercises (biking and resistance training) have been studied as an adjunctive therapy for patients on MHD $[11,12,28]$; though implementation of exercise programs has been partly low due to poor adherence and limited functional capacity of patients [12]. Mind-body practices are often characterized by low intensity and relaxing effects, which may offer better adherence and be applicable to a broader range of patients on MHD than conventional exercise. In addition, the emphasis of both mental and physical engagements during practice may produce distinct physiological, functional, and psychological changes among patients on MHD. Providing mind-body practices during dialysis may increase awareness and access to patients who have not utilized CAM or mindbody practices in the past.

About 1 out of 4 patients on MHD were not interested in learning mind-body practices. Only about half of patients of age 80 years and older or those who had never used CAM 
expressed interest in learning. This is consistent with national data from the general population where fewer elderly patients reported using any CAM or mind-body techniques; only $24 \%$ and $10 \%$ of individuals of age 85 years and older reported use of CAM and mind-body practices, respectively, in the last 12 months [20]. Potential reasons for less interest are lack of familiarity with CAM modalities, belief that they will be unable to participate, resistance to participating in any additional therapy, lack of time, limited access to CAM therapists or classes, or financial constraints. Further research on perceptions and barriers to CAM therapies among patients with chronic disease and elderly patients is needed to explore these differences and to guide implementation of CAM therapies.

Our study has several limitations. Since our sample population was small and derived from a single dialysis center, our results may not reflect CAM use in other regions or nationally. In comparison to national data of the outpatient dialysis population, our sample had a higher proportion of black patients, while it had a similar distribution in age, sex, and causes of ESRD [29]. Data collected were based on selfreport and subject to recall bias. Also, surveys were conducted during MHD among other patients receiving therapy, so subjects may have altered responses due to a lack of privacy. While we utilized standard definitions and questions adapted from nationally based surveys, patients may have a different understanding of what constitutes a CAM therapy. Despite these limitations, our results provide important new insight into CAM use in this chronic disease population.

In summary, CAM use is common among patients with ESRD on MHD, in particular mind-body practices, and is used by a greater percentage of females than males, middleaged than elderly, and patients with higher education levels. Patients largely expressed interest to learn and participate in studies of mind-body therapies. While CAM use, including mind-body therapies, is frequent in the general population and patients with chronic diseases, there exists limited evidence on their therapeutic efficacy [30]. Further research to develop and evaluate mind-body therapies in patients with ESRD is warranted.

\section{Acknowledgments}

Dr. Phillips is supported by a Mid-Career Investigator Award (K24-AT000589) and Dr. Birdee by a Career Development Award (K-23-AT006965) from the National Center for Complementary and Alternative Medicine, National Institute of Health. The authors thank Laura Estan R.D. for her assistance with data collection. The contents of this paper are solely the responsibility of the authors and do not necessarily represent the official views of the National Center for Complementary and Alternative Medicine or the National Institutes of Health.

\section{References}

[1] U.S. Renal Data System. USRDS, "Atlas of chronic kidney disease and end-stage renal disease in the United States," Annual Data Report, National Institutes of Health, National Institute of Diabetes and Digestive and Kidney Diseases, Bethesda, Md, USA, 2010.

[2] R. N. Foley, P. S. Parfrey, and M. J. Sarnak, "Clinical epidemiology of cardiovascular disease in chronic renal disease," American Journal of Kidney Diseases, vol. 32, supplement 3, no. 5, pp. S112-S119, 1998.

[3] R. W. Evans, D. L. Manninen, L. P. Garrison Jr. et al., "The quality of life of patients with end-stage renal disease," New England Journal of Medicine, vol. 312, no. 9, pp. 553-559, 1985.

[4] D. L. Mapes, A. A. Lopes, S. Satayathum et al., "Health-related quality of life as a predictor of mortality and hospitalization: the dialysis outcomes and practice patterns study (DOPPS)," Kidney International, vol. 64, no. 1, pp. 339-349, 2003.

[5] K. L. Johansen, G. M. Chertow, A. V. Ng et al., "Physical activity levels in patients on hemodialysis and healthy sedentary controls," Kidney International, vol. 57, no. 6, pp. 2564-2570, 2000.

[6] P. B. DeOreo, "Hemodialysis patient-assessed functional health status predicts continued survival, hospitalization, and dialysisattendance compliance," American Journal of Kidney Diseases, vol. 30, no. 2, pp. 204-212, 1997.

[7] K. L. Johansen, G. M. Chertow, M. da Silva, S. Carey, and P. Painter, "Determinants of physical performance in ambulatory patients on hemodialysis," Kidney International, vol. 60, no. 4, pp. 1586-1591, 2001.

[8] H. Taskapan, F. Ates, B. Kaya et al., "Psychiatric disorders and large interdialytic weight gain in patients on chronic haemodialysis," Nephrology, vol. 10, no. 1, pp. 15-20, 2005.

[9] F. E. M. Murtagh, J. Addington-Hall, and I. J. Higginson, "The prevalence of symptoms in end-stage renal disease: a systematic review," Advances in Chronic Kidney Disease, vol. 14, no. 1, pp. 82-99, 2007.

[10] J. Himmelfarb and T. A. Ikizler, "Medical progress: hemodialysis," New England Journal of Medicine, vol. 363, no. 19, pp. 1833$1845,2010$.

[11] B. S. B. Cheema, "Review article: tackling the survival issue in end-stage renal disease: time to get physical on haemodialysis," Nephrology, vol. 13, no. 7, pp. 560-569, 2008.

[12] B. S. B. Cheema and M. A. Fiatarone Singh, "Exercise training in patients receiving maintenance hemodialysis: a systematic review of clinical trials," American Journal of Nephrology, vol. 25, no. 4, pp. 352-364, 2005.

[13] K. L. Johansen, "Exercise in the end-stage renal disease population," Journal of the American Society of Nephrology, vol. 18, no. 6, pp. 1845-1854, 2007.

[14] P. Painter, "Physical functioning in end-stage renal disease patients: update 2005," Hemodialysis International, vol. 9, no. 3, pp. 218-235, 2005.

[15] E. Kouidi, "Health-related quality of life in end-stage renal disease patients: the effects of renal rehabilitation," Clinical Nephrology, vol. 61, supplement 1, pp. S60-S71, 2004.

[16] P. Painter, L. Carlson, S. Carey, S. M. Paul, and J. Myll, "Low-functioning hemodialysis patients improve with exercise training," American Journal of Kidney Diseases, vol. 36, no. 3, pp. 600-608, 2000.

[17] K. L. Johansen, G. K. Sakkas, J. Doyle, T. Shubert, and R. Adams Dudley, "Exercise counseling practices among nephrologists caring for patients on dialysis," American Journal of Kidney Diseases, vol. 41, no. 1, pp. 171-178, 2003.

[18] E. Konstantinidou, G. Koukouvou, E. Kouidi, A. Deligiannis, and A. Tourkantonis, "Exercise training in patients with endstage renal disease on hemodialysis: comparison of three 
rehabilitation programs," Journal of Rehabilitation Medicine, vol. 34, no. 1, pp. 40-45, 2002.

[19] "What is CAM?" http://nccam.nih.gov/health/whatiscam/.

[20] P. M. Barnes, B. Bloom, and R. L. Nahin, "Complementary and alternative medicine use among adults and children: United States, 2007," National Health Statistics Reports, no. 12, pp. 1-23, 2009.

[21] H. J. Duncan, S. Pittman, A. Govil et al., "Alternative medicine use in dialysis patients: potential for good and bad!," Nephron Clinical Practice, vol. 105, no. 3, pp. c108-c113, 2007.

[22] S. Hess, S. de Geest, K. Halter, M. Dickenmann, and K. Denhaerynck, "Prevalence and correlates of selected alternative and complementary medicine in adult renal transplant patients," Clinical Transplantation, vol. 23, no. 1, pp. 56-62, 2009.

[23] R. Nowack, C. Ballé, F. Birnkammer, W. Koch, R. Sessler, and R. Birck, "Complementary and alternative medications consumed by renal patients in Southern Germany," Journal of Renal Nutrition, vol. 19, no. 3, pp. 211-219, 2009.

[24] S. H. Saydah and M. S. Eberhardt, "Use of complementary and alternative medicine among adults with chronic diseases: United States 2002," Journal of Alternative and Complementary Medicine, vol. 12, no. 8, pp. 805-812, 2006.

[25] M. Yurtkuran, A. Alp, M. Yurtkuran, and K. Dilek, "A modified yoga-based exercise program in hemodialysis patients: a randomized controlled study," Complementary Therapies in Medicine, vol. 15, no. 3, pp. 164-171, 2007.

[26] T. J. Tsai, J. S. Lai, S. H. Lee et al., "Breathing-coordinated exercise improves the quality of life in hemodialysis patients," Journal of the American Society of Nephrology, vol. 6, no. 5, pp. 1392-1400, 1995.

[27] S. Mustafa, L. Cooper, N. Langrick, N. Simon, S. V. Jassal, and D. G. Oreopoulos, "The effect of a Tai Chi exercise program on quality of life in patients on peritoneal dialysis: a pilot study," Peritoneal Dialysis International, vol. 25, no. 3, pp. 291-294, 2005.

[28] K. L. Johansen, "Exercise and dialysis," Hemodialysis International, vol. 12, no. 3, pp. 290-300, 2008.

[29] N. G. Kutner, K. L. Johansen, G. A. Kaysen et al., "The comprehensive dialysis study (CDS): a USRDS special study," Clinical Journal of the American Society of Nephrology, vol. 4, no. 3, pp. 645-650, 2009.

[30] M. B. Ospina, K. Bond, M. Karkhaneh et al., "Meditation practices for health: state of the research," Evidence Report: Technology Assessment, no. 155, pp. 1-263, 2007. 


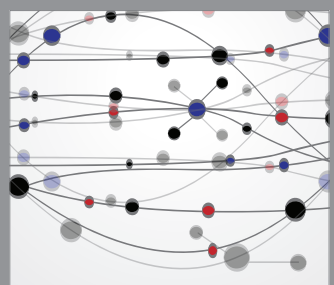

The Scientific World Journal
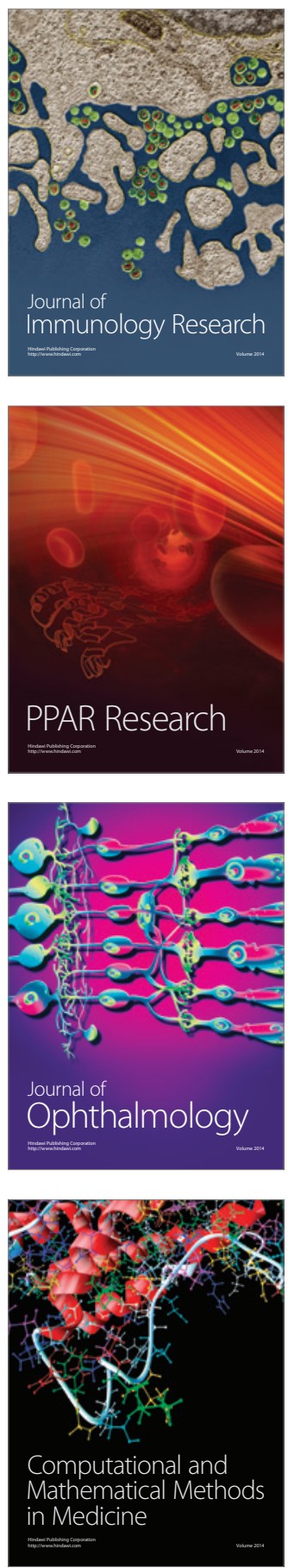

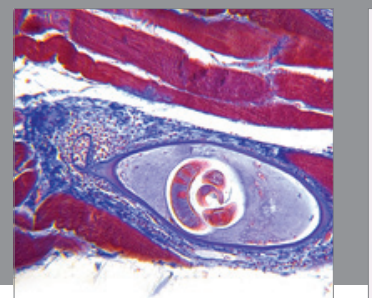

Gastroenterology

Research and Practice
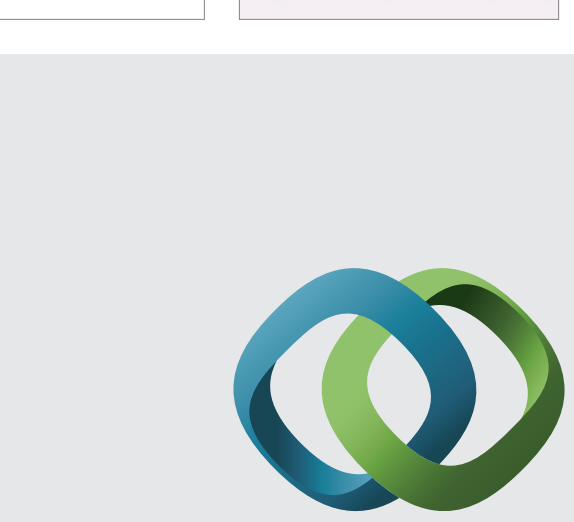

\section{Hindawi}

Submit your manuscripts at

http://www.hindawi.com
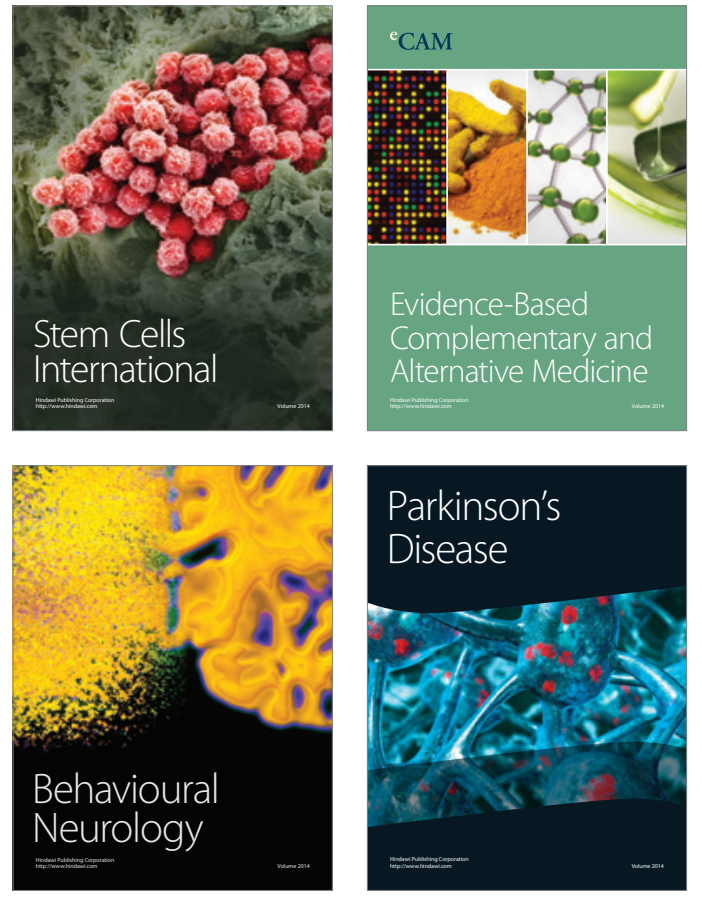
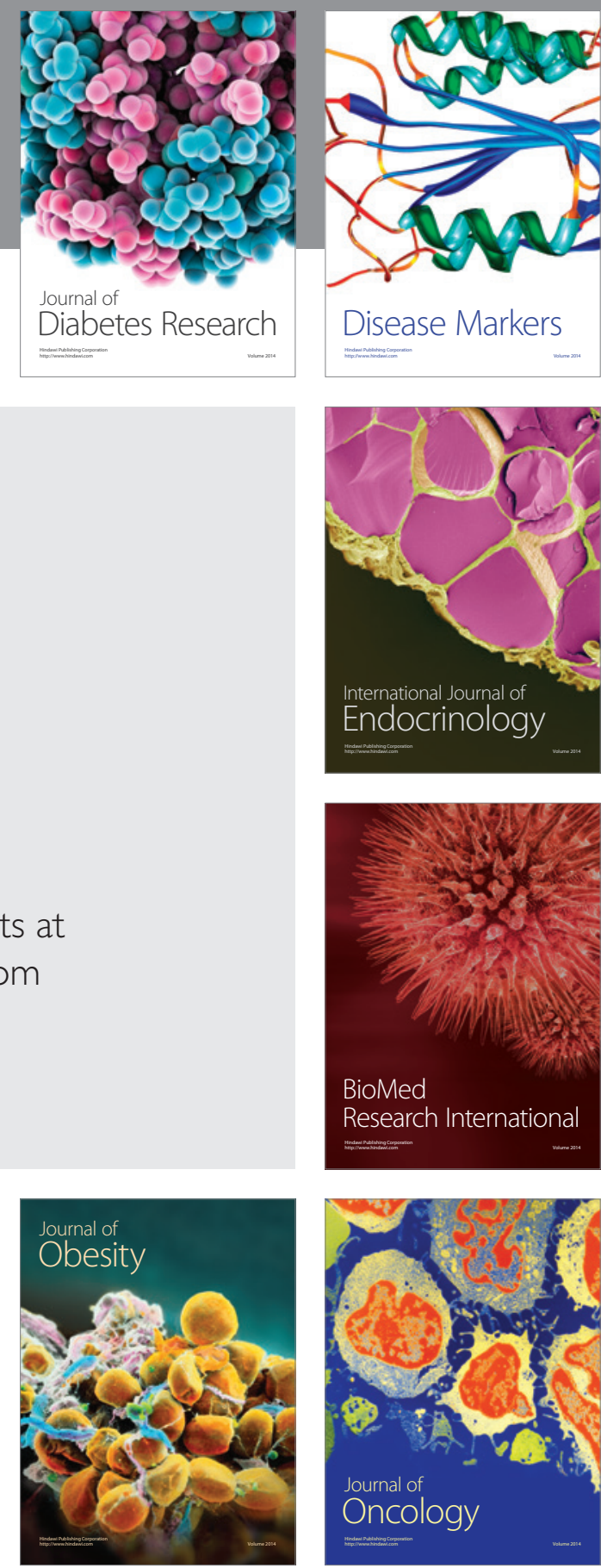

Disease Markers
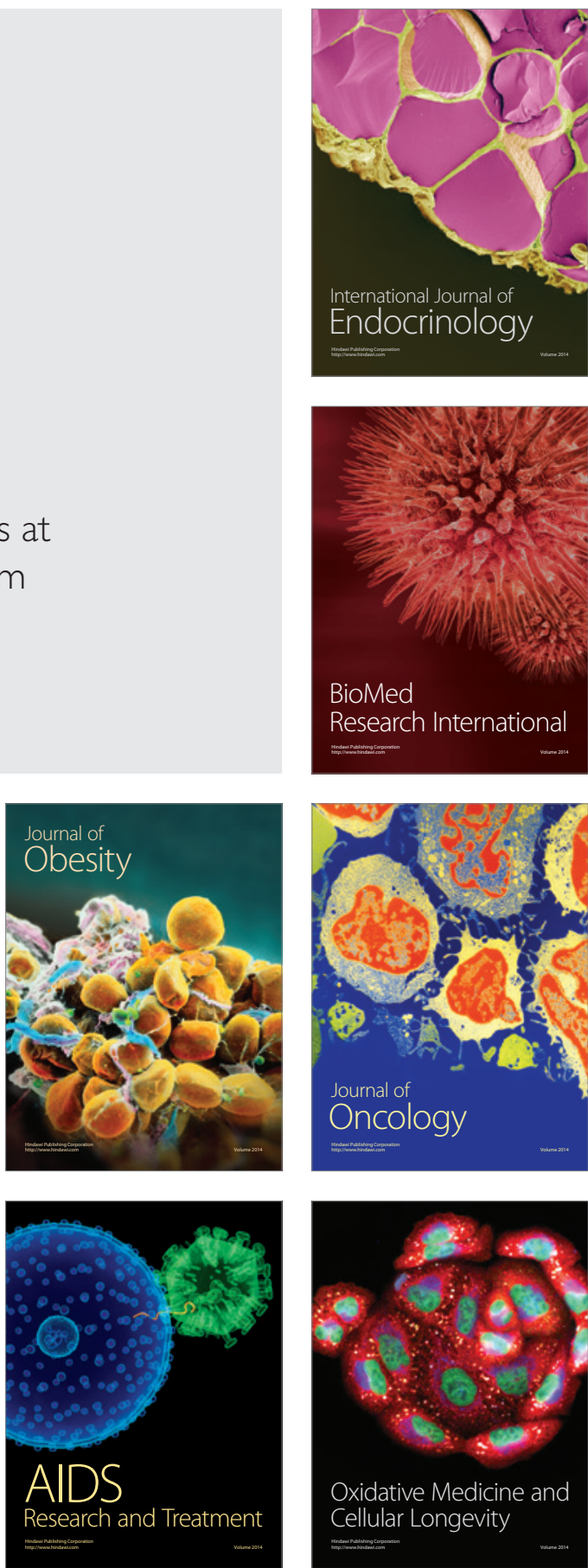